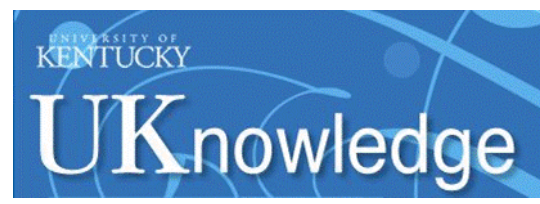

University of Kentucky

UKnowledge

8-1-2012

\title{
College Drinking: A Call to Physicians
}

\author{
Shawn Sorrel \\ University of Kentucky \\ Hatim A. Omar \\ University of Kentucky, hatim.omar@uky.edu
}

Follow this and additional works at: https://uknowledge.uky.edu/pediatrics_facpub

Part of the Community Health and Preventive Medicine Commons, Health Services Administration Commons, Higher Education Commons, and the Substance Abuse and Addiction Commons

Right click to open a feedback form in a new tab to let us know how this document benefits you.

\section{Repository Citation}

Sorrel, Shawn and Omar, Hatim A., "College Drinking: A Call to Physicians" (2012). Pediatrics Faculty Publications. 246.

https://uknowledge.uky.edu/pediatrics_facpub/246

This Review is brought to you for free and open access by the Pediatrics at UKnowledge. It has been accepted for inclusion in Pediatrics Faculty Publications by an authorized administrator of UKnowledge. For more information, please contact UKnowledge@lsv.uky.edu. 


\section{College Drinking: A Call to Physicians}

Digital Object Identifier (DOI)

https://doi.org/10.1515/ijdhd-2012-0031

\section{Notes/Citation Information}

Published in International Journal on Disability and Human Development, v. 11, issue 3, p. 181-183.

(C) 2012 by Walter de Gruyter Berlin Boston

The copyright holder has granted permission for posting the article here.

Reprinted as a book chapter in University and College Students: Health and Development Issues for the Leaders of Tomorrow. Daniel T. L. Shek, \& Rachel C. F. Sun, (Eds.). p. 3-7. 


\section{Review}

\section{College drinking: a call to physicians}

\author{
Shawn Sorrel and Hatim A. Omar* \\ Division of Adolescent Medicine, Department of \\ Pediatrics, UK Healthcare, University of Kentucky \\ College of Medicine, Lexington, KY, USA
}

\begin{abstract}
The aim of this paper was to review literature related to prevalence of drinking on college campuses and current prevention practices targeting this population. This paper focuses on current data surrounding alcohol use and misuse. It further discusses strategies which have been successful to prevent alcohol abuse. Finally, it discusses the need for further research to determine the role of the physician in alcohol prevention at university student health services.
\end{abstract}

Keywords: alcohol; drinking; prevention; students.

\section{Introduction}

Alcohol use continues to be a major concern among colleges and universities. Despite the legal drinking age of 21 years, alcohol consumption among college students is widely accepted. Moreover, although alcohol use has been the target of nationwide prevention and intervention programs, moderate to heavy drinking continues to be prevalent on college campuses. Eighty percent of college students drink alcohol (1). Defining moderate to heavy drinking has been somewhat controversial. The term "binge drinking" has been widely accepted to describe the consumption of five or more drinks for men or four or more drinks for women per drinking occasion. A survey of college students of a nationally representative sample found that 4 in 10 college students had participated in binge drinking during the previous 2 weeks (1).

In the past 13 years, there has been significant research devoted to understanding the prevalence of alcohol use on campuses as well as understanding the trends related to this

*Corresponding author: Professor HatimA. Omar, MD, FAAP, Director of Adolescent Medicine and Young Parent Programs, J422 Kentucky Clinic, Department of Pediatrics, Kentucky Children's Hospital, University of Kentucky College of Medicine, Lexington, KY 40536, USA

E-mail: haomar2@uky.edu

Received September 1, 2011; accepted October 22, 2011 phenomenon. In 1998, the National Advisory Council of the National Institute on Alcohol Abuse and Alcoholism (NIAAA) created a task force to evaluate the research that has been completed on college drinking to recommend future research targets as well as educational programs to be implemented in college campuses. In the initial study, it was found that, in 1998, more than 1400 students aged 18-24 years and enrolled in 2- and 4-year college courses died from alcohol related unintentional injuries, including motor vehicles crashes. Two million college students drove under the influence of alcohol, and more than 3 million rode with a drunk driver in the previous year. More than 500,000 full time 4-year college students were unintentionally injured under the influence of alcohol, more than 600,000 were assaulted, and over 70,000 experienced date rape or sexual assault caused by another student who had been drinking (2). Unfortunately, these statistics are on the rise. In 1998, the proportion of college students who reported driving under the influence of alcohol was $26.5 \%$ and increased to $31.4 \%$ in 2001 . Furthermore, from 1998 to 2001, alcohol-related unintentional injury deaths per 100,000 college students increased by $6 \%(3,4)$. In 2005 , these data were again reevaluated via surveys to determine trends of alcohol use on college campuses. From 1999 to 2002 and then again in 2005, based on the Substance Abuse and Mental Health Services Administration national surveys, the proportion of 18- to 24-year old college students who drank five or more drinks in a single occasion in the previous 30 days increased from $41.7 \%$ to $43.2 \%$ and $44.7 \%$, respectively (5).

From 1999 to 2002, the proportion of college students aged 18-24 years who drove under the influence of alcohol increased significantly from $26.9 \%$ to $31.4 \%$; however, in 2005 , the proportion was lower at $28.9 \%$. Among 18 - to 24-year old college students, deaths from all alcohol-related unintentional injuries, including traffic and other unintentional injuries, increased by $3 \%$. Alcohol is being abused by students aged 18-24-years old both in and out of college at alarming rates. In 2005, this age group of nearly 12 million (both in college and not in college) consumed five or more drinks on at least one occasion in the past month, and more than 7 million drove under the influence of alcohol in the past year. Injuries are the leading cause of death in this age group, and alcohol is a crucial factor in more than 5000 deaths each year (5).

In the general college population, there are higher incidences of high-risk drinking and substance use among members of social fraternities and sororities (6). A study published by McCabe et al. (7) in 2005 found that compared with non- 
members, more fraternity and sorority members engaged in binge drinking during the 2 weeks prior to the study (42\% of men, $29 \%$ of women) (7). Furthermore, Cashin et al. (8) found that the average number of drinks consumed per week is significantly higher for Greek fraternity and sorority members (men consumed 12 drinks per week and women 6 drinks per week) than for non-Greek fraternity and sorority members (men: 6 drinks, women: 2 drinks).

\section{The early years ... when does it start?}

Indeed, some students do not begin to enagage in abnormal drinking patterns until after starting college. However, for some students, patterns of heavy drinking have been established during their high school career. Data from the National Longitudinal Alcohol Epidemiologic Study revealed an indirect relationship between the age of onset of alcohol use and increasing prevalence of lifetime alcohol dependence and abuse. Essentially, the earlier one starts to enage in drinking, the higher the risk of developing alcohol abuse and dependence (9). For those aged 12 years or younger at first use, the prevalence of lifetime alcohol dependence was $40.6 \%$; however, the rates for those who started drinking at 18 and 21 years were $16.6 \%$ and $10.6 \%$, respectively (10).

Significant research has shown that the transition period between high school and college may be an important period to target intervention and prevention programs. Wechsler et al. (1) found that $80 \%$ of high school heavy episodic drinkers are likely to be college student heavy drinkers. However, a significant number of men who exhibit heavy drinking tendencies in college may not be identified as being at risk as a function of their college drinking behavior in high school. For many young men and women, heavy drinking occurs for the first time during their first year of college (11). The American Academy of Pediatrics recognizes the prevalence of high risk drinking in college students and its role in intervention and prevention. In a policy statement published in 2010, specific recommendations to address the problem were made for pediatricians and other health providers who work with children. Recommendations included (but not limited to) recognizing risk factors associated to alcohol use and identifying comorbid conditions; screening for current alcohol use (and other drugs) in adolescents and young adults and referring patients for intervention when appropriate; using brief intervention techniques in the clinical setting and being familiar with motivational interviewing techniques to work with patients who use alcohol; and supporting adovacy efforts and further research (12).

\section{What is being done?}

Existing information to combat overconsumption of alcohol on college campuses is overwhelming. In 2002, the Task Force on College Drinking from the National Institute on Alcohol Abuse and Alcoholism issued a report, "A Call to Action: Changing the Culture of Drinking at US Colleges".
The foundation of the report is based on the concept that successful interventions occur on three levels, termed the 3-in-1 approach. The first level targets individuals and makes recommendation to address at-risk or alcohol-dependent drinkers. Recommendations are made to support strategies for individual screening. An example provided in the report is the National Alcohol Screening Day, which provides free, anonymous testing and health information pertaining to alcohol use (13).

The second level, which targets the student body, addresses policy and legislation that would address the factors encouraging high risk drinking, such as availabilility of alcoholic beverages to underage and intoxicated students. The third and final level encompasses the college and surrounding community under the premise that reinforcing intervention within the alliance between college and the surrounding community can change the broader environment and help reduce alcohol abuse and alcohol-related problems over the long-term.

Research shows that brief intervention and motivational interviewing are promising methods for intervention. A metaanalysis was completed, which included 62 studies published between 1985 to early 2007. Findings of this review revealed that face to face interventions using motivational interviews and personalized normative feedback predict greater reductions in alcohol-related problems (14). A study also found that brief motivational interviewing and then mailing feedback about their drinking to students leads to reduced alcohol consumption after 6 weeks (15). One of the most well-known programs for feedback intervention is the Brief Alcohol Screening and Intervention for College Students (BASICS) program developed by Dimeff and associates and published in 1999. Although the results are most promising for heavier college drinkers, follow-up assessments after 2 years following the intervention reveal decreased rates in drinking and harmful consequences (16).

Today's college population is possibly the most technologically advanced population, and utilizing this aspect has been proposed as part of intervention programs focused on college drinking habits. Chiauzzi et al. proposed a prevention web site, "My Student Body.com:Alcohol" (MSB:Alcohol), which offers a brief and personalized intervention program to help decrease drinking among college students who drink heavily. The positive results show that using a technological tool for intervention may play an important role in the future (17).

\section{A call to physicians: what is our role?}

The role of the physician in the patient-physician relationship is a fiduciary relationship or "trust", creating a "bond" between the two. In comparison, the historical model gave a more authoritarian role to the physician and often took less consideration of the patient's preferences. Today, this relationship has evolved into one, in which the physician provides wholistic treatment while considering the patient's personal values and beliefs. What has not changed over time, 
however, is the uniqueness of this relationship. The potential that exists for a physician to have a impact on someone's life is a priviledge, and providing intervention when one is making harmful choices is our job.

College health services provide care to thousands of college students on a daily basis. Students use the often free or low cost health services on college campuses for preventative care and visits related to acute illnesses. Clearly, the statistics show that drinking on college campuses is on the rise as are the harmful and fatal effects resulting from this epidemic. There is an overwhelming amount of research targeting campus and community prevention and intervention. Some of the most promising studies show that one-on-one conversations about a student's drinking habits can have an effect on his/ her alcohol consumption; however, there is a lack of data to reflect the conversations that occur between students and physicians. Again, the question needs to be asked, as physicians, "Are we doing our job?"

\section{Conflict of interest statement}

Authors' conflict of interest disclosure: The authors stated that there are no conflicts of interest regarding the publication of this article.

Research funding: None declared.

Employment or leadership: None declared.

Honorarium: None declared.

\section{References}

1. Wechsler H, Lee J, Kuo M, Lee H. College binge drinking in the 1990s - A continuing problem: results of the Harvard School of Public Health 1999 college alcohol study. J Am Coll Health 2000;48: 199-210.

2. Hingson RW, Heeren T, Zakocs RC, Kopstein A, Wechsler H. Magnitude of alcohol-related mortality and morbidity among U.S. college students ages 18-24. J Stud Alcohol 2002;63: 136-44.

3. Hingson R, Heeren T, Winter M, Wechsler H. Magnitude of alcohol-related mortality and morbidity among U.S. college students ages 18-24: changes from 1998 to 2001. Annu Rev Pub! Hlth 2005;26: 259-79.
4. National Institute on Alcohol Abuse and Alcoholism. What colleges need to know now: an update on college drinking research. Bethesda, MD: NIH Publication No. 07-5010, National Institute on Alcohol Abuse and Alcoholism, 2007.

5. Hingson R, Wenzing Z, Weitzman E. Magnitude of and trends in. alcohol-related mortality and morbidity among US college students 18-24, 1998-2005. J Stud Alcohol 2009;16:12-20.

6. Alva SA. Self-reported alcohol use of college fraternity and sorority members. J Coll Stud Dev 1998;39:3-10.

7. McCabe SE, Schulenberg JE, Johnston LD, O'Malley PM, Bachman JG, Kloska DD. Selection and socialization effects of fraternities and sororities on U.S. college student substance use: a multi-corhort national longitudinal study. Addiction 2005; 100:512-24.

8. Cashin JR, Presley CA, Meilman PW. Alcohol use in the Greek system: folllow the leader? J Stud Alcohol 1998;59:63-70.

9. US Department Health Human Services. National epidemiologic surverys on alcohol and related conditions. Bethesda, MD: National Institutes Health, Alcohol Alert 70, 2006.

10. Grant BF, Stinson FS, Harford TC. Age at onset of alcohol use and DSM-IV alcohol abuse and dependence: a 12 year follow-up. J Subst Abuse 2001;13:493-504.

11. Wechsler H, Davenport A, Dowdall G, Moeykens B, Castillo S. Health and behavioral consequences of binge drinking in college: a national survey of students at 140 campuses. J Am MedAssoc 1994;272:1672-7.

12. Committee on Substance Abuse, American Academy of Pediatrics. Alcohol use by youth and adolescents: a pediatric concern. Pediatrics 2010;125:1078-87.

13. NIH. A call to action: changing the culture of drinking at US colleges. Bethesda, MD: National Institute Health Publications, National Institute Alcohol Abuse Alcoholism, No 02-5010, 2002.

14. Carey KB, Scott-Sheldon LA, Carey MP, DeMartini KS. Individual-level interventions to reduce college student drinking: a meta-analytic review. Addict Behav 2007;32:2469-94.

15. Walters ST. In praise of feedback: notes on an effective intervention for heavy drinking college students. J Am Coll Health 2000;48:235-8.

16. Dimeff LA, Baer JS, Kivlahan DR, Baer JS, Marlatt GA. Individual drinking changes following a brief intervention among. college students. J Consult Clin Psychol 2000;68:500--5.

17. Chiauzzi E, Green TC, Lord S, Thum C, Goldstein M. My student body: a high-risk drinking prevention web site for college students. J Am Coll Health 2005;53:263-74. 